\title{
CERN News
}

The Erste Bürgermeister of Heidelberg,

Dr. K. Korz, speaking at the ceremony at CERN

on 10 May when the Agreement establishing

a European molecular biology Laboratory was signed. The Laboratory will be built at

Heidelberg. On his right in the photograph

(from left to right) are W. Jentschke (Director

General of CERN Laboratory I), H. Voirier

(President of the European Molecular Biology

Conference), R. Keller (Director of the

International Organization Board of the Swiss Federal Policy Department), J.C. Kendrew

(Director General designate of the new

Laboratory), R.K. Appleyard (Executive Secretary of EMBO) and M. Delauche (Secretary of $E M B C)$.

\section{European Molecular Biology Laboratory}

On 10 May an Agreement was signed at CERN setting up a new European Laboratory. It will be concerned with research in molecular biology and will be located at Heidelberg in the Federal Republic of Germany.

The Laboratory has been under discussion for several years. It is intended to provide a centre where top-class instrumentation for this type of research could be developed but more importantly to provide a centre where top-class scientists from the various disciplines involved in the study of molecular biology could work together. CERN, besides being the venue for many of the debates concerning the Laboratory, has been used as a model in establishing the principles as to how a European research centre should work. It is intended that the Heidelberg Laboratory will have visiting scientists coming from the Member States. The Laboratory itself is intended to have quite a small complement of 'permanent' scientific staff but will offer sophisticated equipment and a multi-disciplinary environment.

The CERN Convention has been used as a model in drawing up the Agreement on the Laboratory. The Agreement lays down the broad lines of control for the Member States while retaining sufficient flexibility to be able to adapt to the future evolution of the research. The Member States exercise their overall control via a Council of delegates, as at CERN, while the running of the Laboratory is assigned to a Director General. The Director General designate is J.C. Kendrew who has been Project Leader in the studies leading to the establishment of the Laboratory. Professor Kendrew received the Nobel Prize in 1962 for his research on protein structure.

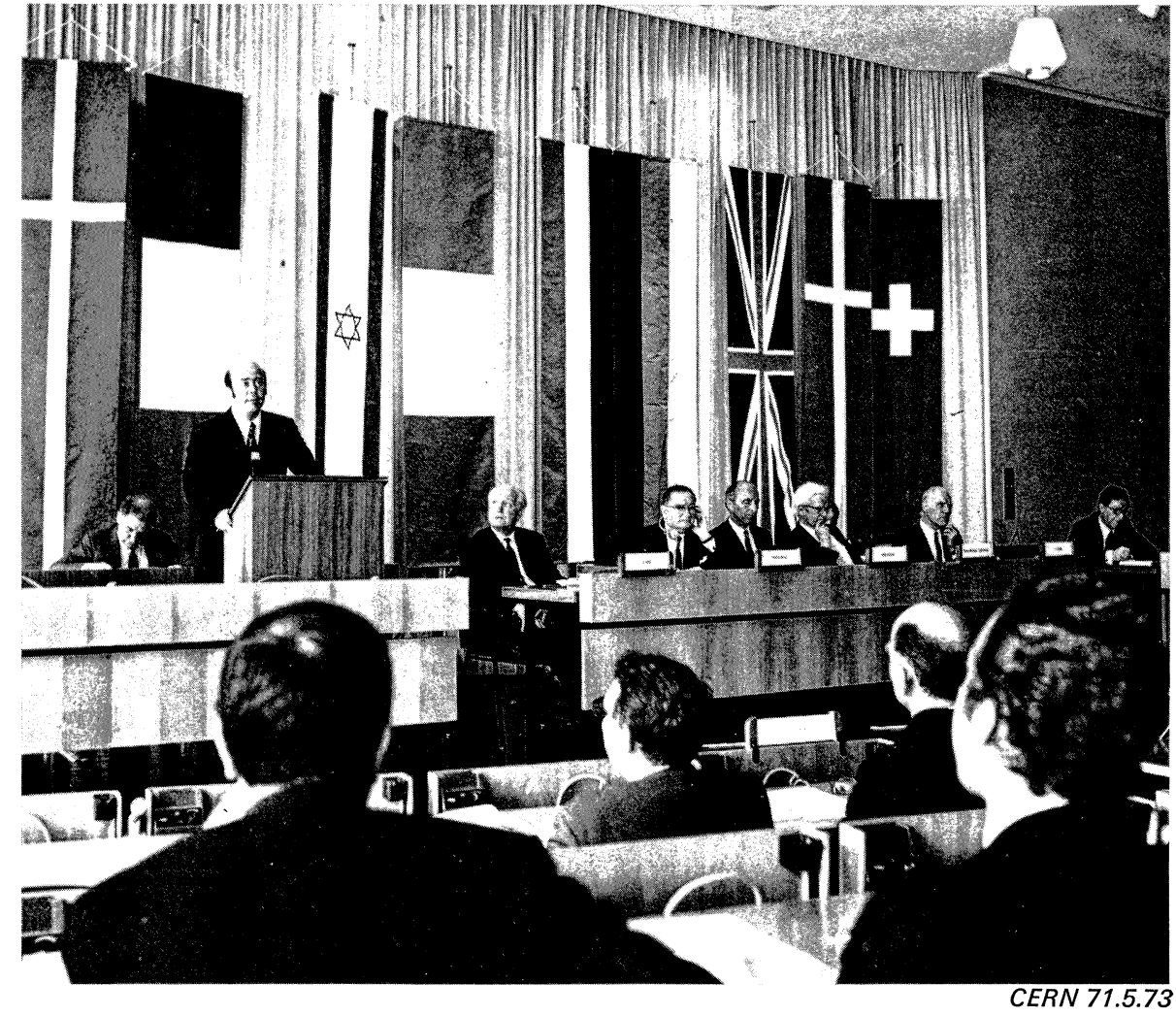

Ten countries have signed the Agreement-Austria, Denmark, Federal Republic of Germany, France, Israel, Italy, the Netherlands, Sweden, Switzerland and the United Kingdom. Greece, Norway and Spain have participated in the discussions but are unable to join at the present time.

The participating countries have agreed to support the Laboratory for a minimum of seven years during which time the capital expenditure is expected to be 11 million accounting units at 1972 prices (an accounting unit is about $\$ 1$ ). This sum includes expenditure at the two research facilities at DESY in Hamburg (using synchrotron radiation) and at LaueLangevin in Grenoble (using neutron beams). Operating costs are expected to grow to 4.2 million accounting units per year.

The Federal Republic of Germany has contributed considerably towards the setting up of the Laboratory. In addition to making available the site, the German government is making a gift of 12 million marks (which reduces the capital expenditure required from the Member States to 7.7 million accounting units over seven years). Heidelberg is helping to provide temporary accommodation so that the project can get off to a fast start.

\section{ECFA Working Group on tripartite relations}

The European Committee for Future Accelerators (ECFA) has for some time been discussing the relationships between CERN, the national high energy physics Laboratories and the Universities in the CERN Member States. ECFA is a natural forum for 